Article

\title{
Evaluation of Radiation Shielding Features of Co and Ni-Based Superalloys Using MCNP-5 Code: Potential Use in Nuclear Safety
}

\author{
M. I. Sayyed ${ }^{1,2, * \mathbb{C}}$, Faras Q. Mohammed ${ }^{3}$, K. A. Mahmoud ${ }^{4,5}{ }^{(}$, Eloic Lacomme ${ }^{6}$, \\ Kawa M. Kaky ${ }^{3,7}$, Mayeen Uddin Khandaker ${ }^{8, *}$ and Mohammad Rashed Iqbal Faruque ${ }^{9}$ (D) \\ 1 Department of Physics, Faculty of Science, Isra University, Amman 11622, Jordan \\ 2 Department of Nuclear Medicine Research, Institute for Research and Medical Consultations, \\ Imam Abdulrahman bin Faisal University, Dammam 31441, Saudi Arabia \\ 3 Nanotechnology and Advanced Materials Research Center, University of Technology, Baghdad 35010, Iraq; \\ 11795@uotechnolrgy.edu.iq (F.Q.M.); kawa.mudher@parliament.iq (K.M.K.) \\ 4 Ural Federal University, St. Mira, 19, 620002 Yekaterinburg, Russia; kmakhmud@urfu.ru \\ 5 Nuclear Materials Authority, Maadi, Cairo 11381, Egypt \\ 6 Advanced Science Research, Junior, Eastchester High School, Eastchester, NY 10709, USA; \\ eloic187521@eufsdk12.org \\ 7 Directorate of Communication and Information Technology, Council of Representatives of Iraq, \\ Conferences Palace, Baghdad 10001, Iraq \\ 8 Center for Biomedical Physics, School of Healthcare and Medical Sciences, Sunway University, \\ Bandar Sunway 47500, Selangor Darul Ehsan, Malaysia \\ 9 Space Science Centre (ANGKASA), Universiti Kebangsaan Malaysia, Bangi 43600, Selangor, Malaysia; \\ rashed@ukm.edu.my \\ * Correspondence: mabualssayed@ut.edu.sa (M.I.S.); mayeenk@sunway.edu.my (M.U.K.)
}

Received: 8 September 2020; Accepted: 27 October 2020; Published: 30 October 2020

\begin{abstract}
Due to their excellent heat resistance, superalloys are used predominantly in the manufacturing of engine parts and accessories for aircraft and aerospace equipment. The Monte Carlo simulation (MCNP-5) code was performed to estimate the mean track length of the incident photons inside six different alloys. Then, based on the simulated track length, other important $\gamma$-ray shielding parameters were calculated. In this study, the highest mass attenuation coefficient was obtained for alloys encoded MAR-302 and MAR-247 and varied in the range 0.035-72.94 and $0.035-71.98 \mathrm{~cm}^{2} \cdot \mathrm{g}^{-1}$, respectively. The lowest mass attenuation coefficient was found for alloys coded Inconel-718 and Nimocast-75 with a range of $0.033-59.25$ and $0.32-59.30 \mathrm{~cm}^{2} \cdot \mathrm{g}^{-1}$, respectively. Use was made of a recently developed online program Phy-X/PD to calculate the effective atomic number, equivalent atomic number, and the buildup factors for the alloys of interest. The effective removal cross-section for the fast neutron was also calculated for the studied alloys: the highest value was found for the alloys coded with Inconel-718 $\left(\sum_{\mathrm{R}}=0.01945 \mathrm{~cm}^{2} \cdot \mathrm{g}^{-1}\right)$ and Nimocast-75 $\left(\sum_{R}=0.01940 \mathrm{~cm}^{2} \cdot \mathrm{g}^{-1}\right)$, and the lowest value was obtained for alloy coded MAR-302 $\left(\sum_{\mathrm{R}}=0.01841 \mathrm{~cm}^{2} \cdot \mathrm{g}^{-1}\right)$. Calculated data indicate that MAR-302 and MAR-247 are superior candidates for shielding of gamma-rays, while Inconel-718 and Nimocast-75 MAR-302 are suitable for the shielding of fast neutrons.
\end{abstract}

Keywords: MCNP; SRIM; superalloys; $\gamma$-ray and neutron; shielding parameters

\section{Introduction}

Technologies that are vital to the fields of medicine, agriculture, energy generation, and more, are based on utilizing different types of radiation to function. Even though this offers a multitude 
of benefits, exposure to some types of radiation can be extremely harmful [1,2]. Radiation exposure can lead to permanent cell damage, cancer, and even death. Based on these risks, it is necessary to implement careful safety measures to protect people who are engaged in applications of radiation on a daily basis in various purposes [3,4].

To reduce the possible harm against radiation, three principles can be used to protect against overexposure: time, distance, and shielding. The latter, shielding, has been widely investigated by researchers in the last couple of decades [5]. Radiation shielding provides a barrier between the radiation source and the person, with the material acting as a medium for reducing the incoming photon intensity. A range of materials are commonly used for the purpose of radiation shielding. Concretes are structurally strong and can be enhanced by introducing metals into its composition; however, they are prone to cracking and wear over time, making other materials possibly more efficient [6-10]. Another material, glass, offers the ability to have a transparent shield while having a wide range of compositions that can be altered to improve its shielding ability [11-15]. Lead is a common element used in radiation shields because of its high density and low cost, which greatly improves the efficiency of the material. As is widely known, however, lead is a highly toxic substance to both humans and their environment. Over recent years, its use has increasingly become more limited. Therefore, substitutes that offer the same efficiency as the lead while being environmentally friendly must be investigated [16].

In recent years, alloys have gained increasing attention as other possible shielding materials. Alloys are metallic substances composed of multiple elements. By creating alloys, the properties of the original metals are enhanced including characteristics such as strength, heat resistance, and shielding ability. Alloys can be classified based on their size, application, or base metal. A multitude of alloys with different base metals has been investigated for their radiation shielding ability. These include nickel, lead, tungsten, copper, iron, and more. Many of these base metals have shown great ability at attenuating radiation, making them viable materials for protection against the adverse effects of ionizing radiation [17-22]. Due to their excellent heat resistance properties, alloys are used predominantly in a wide range of applications, from aircraft and automobiles to electronics and batteries.

Metal atom vibration due to the interaction with the radiation could lead to a reduction in thee ductility of the material. As a result, the breaking of the ionic and covalent bonds take place between the atoms in the materials. This can lead to a change in the material crystal structure, which results in permanent damage to the shielding equipment/materials [23]. Materials used for the purpose of radiation shielding in a reactor environment must have high radiation absorption capacity, a combination of strength and metallurgical stability, and have high resistivity against temperature, chemical corrosion, etc. [24,25]. Materials with a stronger crystal structure such as superalloys can endure these effects and can serve better shielding, mechanical, and chemical performances. Co and $\mathrm{Ni}$-based superalloys have the advantages of resisting many severely corrosive environments and show high resistance to pitting and crevice corrosion. Additionally, superalloys have shown better strength for creep-rupture at temperatures up to $700{ }^{\circ} \mathrm{C}$. Moreover, the sufficiently high density (over $9 \mathrm{~g} \cdot \mathrm{cm}^{-3}$ for some alloys) and good shielding characteristics for $\gamma$-rays and neutrons make it a good choice to be used in many applications such as gas turbines, rocket motors, spacecraft, pollution-control equipment, and nuclear reactors [26].

The efficiency of a material as a radiation shield is defined by calculating certain shielding parameters. The most important one, the mass attenuation coefficient, defines the ability for photons to penetrate through a material and is a good indicator of the viability of a substance. Another common parameter is the half-value layer (HVL), which characterizes the materials' thickness that is able to reduce the intensity of the incoming radiation into half. The mean free path (MFP) is the reciprocal of the mass attenuation coefficient and describes the average distance between collisions, with a lower value meaning a more effective material. Effective atomic number $\left(Z_{\text {eff }}\right)$, the average atomic number of a compound or mixture, is another useful parameter. 


\section{Simulations and Theoretical Aspect}

\subsection{Monte Carlo N-Particle Transport Simulation Code}

Monte Carlo simulation code (MCNP-5) was used to estimate the shielding parameters of the studied alloys in the energy range between 0.015 and $15 \mathrm{MeV}$. All components used in this simulation (such as surface-, cell-, material-, source-, and NPS card) are described in the input file and shown in Figure 1 . The surface and cell cards detail the $(2 \mathrm{~cm}$ in diameter) source that was placed inside one end of a lead collimator with a $2.1 \mathrm{~cm}$ in diameter slit. The studied alloys were placed on the other side of the collimator at a distance of $10 \mathrm{~cm}$ from the $\gamma$-ray source. The alloys were assumed to be a disk $3 \mathrm{~cm}$ in diameter. The composition of the alloys in (wt.\%) is given in Table 1. The detector was considered to be tally F4 to estimate the track length of the cell flux inside the studied alloys. The detector was placed at a distance of $10 \mathrm{~cm}$ from the alloy samples. The source card (SDEF) describes the mono-energetic gamma-ray source placed at the center of a shielded lead cylinder (length $50 \mathrm{~cm}$, diameter $35 \mathrm{~cm}$ ), and the source intensity, distribution, and direction of the photon emission $(+Z)$. The cutoff card NPS was set for the emission of $10^{6}$ histories. Moreover, the MCNP- 5 code can automatically extract the required energy from various nuclear and atomic data libraries such as the Evaluated Nuclear Data File (ENDF) system, Advanced Computational Technology Initiative (ACTI), the Evaluated Nuclear Data Library (ENDL), Evaluated Photon Data Library (EPDL), and the Activation Library (ACTL), etc. [27-29].

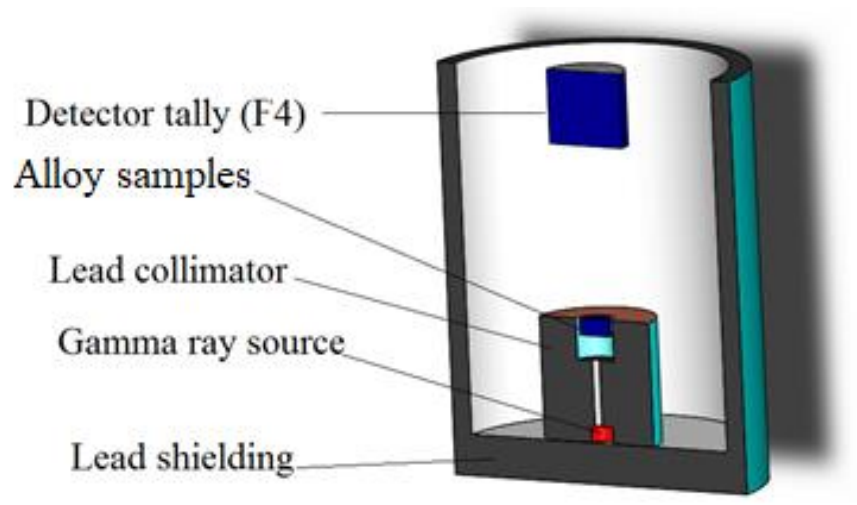

Figure 1. The geometry used for the gamma-ray shielding simulation.

Table 1. The chemical composition of the selected alloys in (wt.\%).

\begin{tabular}{ccccccccccccccccc}
\hline \multirow{2}{*}{$\begin{array}{c}\text { Alloy } \\
\text { Code. }\end{array}$} & $\mathbf{C}$ & $\mathbf{C r}$ & $\mathbf{C o}$ & $\mathbf{M o}$ & $\mathbf{W}$ & $\mathbf{T a}$ & $\mathbf{A l}$ & $\mathbf{T i}$ & $\mathbf{H f}$ & $\mathbf{Z r}$ & $\mathbf{B}$ & $\mathbf{N i}$ & $\mathbf{F e}$ & $\mathbf{N b}$ & $\begin{array}{c}\text { Density } \\
\left(\mathbf{g} \cdot \mathbf{c m}^{-3}\right)\end{array}$ \\
\hline & MAR-247 & 0.02 & 8.50 & 10.00 & 0.65 & 10.00 & 3.00 & 5.60 & 1.00 & 1.40 & 0.04 & 0.02 & 59.63 & 0.00 & 0.00 & 8.53 \\
\hline MAR-302 & 0.85 & 21.50 & 56.94 & 0.00 & 10.00 & 9.00 & 0.00 & 0.20 & 0.00 & 0.00 & 0.01 & 0.00 & 1.50 & 0.00 & 9.21 \\
\hline Inconel-625 & 0.00 & 21.50 & 0.00 & 9.00 & 0.00 & 0.00 & 0.20 & 0.20 & 0.00 & 0.00 & 0.00 & 61.00 & 2.00 & 3.60 & 8.44 \\
\hline Inconel-718 & 0.00 & 19.00 & 0.00 & 3.00 & 0.00 & 0.00 & 0.50 & 0.90 & 0.00 & 0.00 & 0.00 & 52.50 & 18.50 & 5.10 & 8.22 \\
\hline Nimocast-75 & 0.12 & 20.00 & 0.00 & 0.00 & 0.00 & 0.00 & 0.00 & 0.00 & 0.00 & 0.00 & 0.00 & 79.88 & 0.00 & 0.00 & 8.44 \\
\hline WI-52 & 0.85 & 21.50 & 63.65 & 0.00 & 11.00 & 0.00 & 0.00 & 0.00 & 0.00 & 0.00 & 0.00 & 1.00 & 2.00 & 0.00 & 8.88 \\
\hline
\end{tabular}

\subsection{Radiation Shielding Parameter Calculation}

The simulated track length was used to calculate the linear attenuation coefficient (LAC) of the studied alloys in the mentioned energy range. The mass attenuation coefficient (MAC) is calculated based on the simulated average track length and LAC, as described in Equation (1). The MAC is used to describe the capacity of a given material to attenuate incident radiation. Aside from the evaluation of the MAC using the Monte Carlo simulation, it was calculated theoretically using XCOM software. 
The MAC for any material consists of the ith constituent element and can be calculated according to Equation (2) [1].

$$
\begin{gathered}
(M A C)_{\text {alloy }}=\frac{L A C}{\rho\left(\mathrm{g} \mathrm{cm}^{-3}\right)} \\
(M A C)_{\text {alloy }}=\sum_{i} \omega_{i} *(M A C)_{i}
\end{gathered}
$$

where $(M A C)_{a l l o y}, \omega_{i}, \rho$, and $(M A C)_{i}$ refer to the MAC of the studied alloys, the weight fraction, and MAC for the ith constituent element, respectively.

The half value layer (HVL) is calculated based on the results of the linear attenuation coefficient (LAC, or $\mu$ ) as presented in Equation (3). The HVL describes the thickness of the material required to diminish the incident intensity to a half of its initial value.

$$
H V L=\frac{\ln (2)}{\mu\left(\mathrm{cm}^{-1}\right)}
$$

The MFP refers to the distance that the radiation travels in the studied shielding materials between two subsequent collisions and can be calculated according to Equation (4).

$$
M F P=\frac{1}{\mu\left(\mathrm{cm}^{-1}\right)}
$$

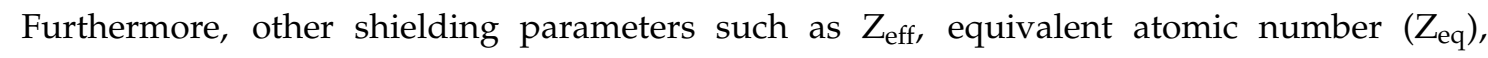
geometric progression fitting parameters exposure buildup factor (EBF), and energy absorption buildup factor (EABF) were calculated using a newly developed software, Phy-X/PSD, in the energy range of $0.015-15 \mathrm{MeV}$ [30]. The SRIM program was used to calculate the stopping power and projected range of the protons and alpha particles [31].

\section{Results and Discussion}

The MCNP-5 simulated MAC values for the studied alloys and calculated MAC values using the XCOM software are presented in Table 2 and Figure 2. The maximum MAC values for all the investigated alloys were achieved at a low photon energy of $0.015 \mathrm{MeV}$. The maximum MAC values varied between 72.938 and $59.259 \mathrm{~cm}^{2} \cdot \mathrm{g}^{-1}$ for alloys encoded as MAR-302 and Nimocast-75, respectively. The MAC values sharply decrease with the increase in gamma energy because of the photoelectric interaction (PE). Around a gamma photon energy of $0.02 \mathrm{MeV}$, a slight increment in the MAC values was observed for the Inconel-625 and Inconel 718 alloys. This small increase was due to the K-absorption edges of niobium $(\mathrm{Nb})$ and tantalum $(\mathrm{Ta})$, which appeared at 0.019 and $0.02 \mathrm{MeV}$, respectively. The small increase in the MAC values reflects the small concentration of $\mathrm{Nd}$ and $\mathrm{Ta}$ in the Inconel-625 and Inconel 718 alloys. Another increase in the MAC values was observed around $0.07 \mathrm{MeV}$ for alloys encoded as MAR-302, MAR-247, and WI-52. This peak was due to the K-absorption edge of tungsten (W), which appears at $0.069 \mathrm{MeV}$. Above $0.2 \mathrm{MeV}$, the MAC values reduced more slowly with the increase in the incident photon energy because of the dominance of Compton scattering (CS) at this energy, which is proportional to Z.E ${ }^{-1}[14,32]$. Above several MeV, the MAC values demonstrated a reverse trend and had a slightly upward trend when increasing the incident photon energy. This slight upward trend was due to the pair production (PP) process, which is proportional to $Z^{2}$.Log (E) [33]. The lowest MAC was achieved at high gamma photon energy $(15 \mathrm{MeV})$ and varied in the range of $0.0323-0.0348 \mathrm{~cm}^{2} \cdot \mathrm{g}^{-1}$ for alloys encoded as MAR-302 and Inconel-625. 
Table 2. The simulated and calculated mass attenuation coefficients for the studied alloys.

\begin{tabular}{|c|c|c|c|c|c|c|c|c|c|c|c|c|c|c|c|c|c|c|}
\hline \multirow{3}{*}{$\begin{array}{l}\text { Energy } \\
(\mathrm{MeV})\end{array}$} & \multicolumn{18}{|c|}{ The Mass Attenuation Coefficient $\left(\mathrm{cm}^{2} \cdot \mathrm{g}^{-1}\right)$} \\
\hline & \multicolumn{2}{|c|}{ MAR-274 } & \multirow[b]{2}{*}{ Diff (\%) } & \multicolumn{3}{|c|}{ MAR-302 } & \multicolumn{3}{|c|}{ Inconel 625} & \multicolumn{3}{|c|}{ Inconel 718} & \multicolumn{3}{|c|}{ Nimocast } & \multicolumn{3}{|c|}{ WI-52 } \\
\hline & MCNP-5 & XCOM & & MCNP-5 & XCOM & Diff (\%) & MCNP-5 & XCOM & Diff (\%) & MCNP-5 & XCOM & Diff (\%) & MCNP-5 & XCOM & Diff (\%) & MCNP-5 & XCOM & Diff (\%) \\
\hline 0.015 & 71.987 & 73.030 & 1.449 & 72.938 & 72.025 & 1.252 & 65.726 & 65.708 & 0.027 & 59.259 & 59.004 & 0.431 & 59.309 & 57.783 & 2.573 & 66.368 & 66.245 & 0.185 \\
\hline 0.03 & 10.873 & 11.140 & 2.458 & 11.142 & 10.863 & 2.505 & 9.557 & 9.549 & 0.075 & 11.056 & 10.418 & 5.771 & 10.939 & 11.357 & 3.818 & 9.858 & 9.830 & 0.282 \\
\hline 0.05 & 2.692 & 2.746 & 2.021 & 2.741 & 2.698 & 1.570 & 2.288 & 2.287 & 0.064 & 2.630 & 2.519 & 4.246 & 2.636 & 2.758 & 4.623 & 2.414 & 2.412 & 0.083 \\
\hline 0.8 & 0.069 & 0.070 & 1.840 & 0.070 & 0.069 & 1.420 & 0.068 & 0.068 & 0.142 & 0.068 & 0.067 & 0.541 & 0.068 & 0.066 & 2.186 & 0.068 & 0.068 & 0.121 \\
\hline 1 & 0.060 & 0.062 & 3.596 & 0.061 & 0.060 & 0.673 & 0.061 & 0.061 & 0.954 & 0.060 & 0.060 & 0.422 & 0.060 & 0.059 & 1.437 & 0.059 & 0.060 & 0.945 \\
\hline 3 & 0.037 & 0.037 & 2.570 & 0.037 & 0.037 & 1.556 & 0.037 & 0.037 & 0.420 & 0.037 & 0.037 & 0.446 & 0.037 & 0.036 & 1.739 & 0.036 & 0.036 & 0.157 \\
\hline 5 & 0.033 & 0.033 & 1.752 & 0.033 & 0.033 & 1.146 & 0.032 & 0.032 & 0.293 & 0.032 & 0.032 & 1.056 & 0.032 & 0.032 & 1.400 & 0.032 & 0.032 & 0.003 \\
\hline 8 & 0.032 & 0.033 & 1.043 & 0.033 & 0.032 & 0.636 & 0.031 & 0.031 & 0.227 & 0.031 & 0.031 & 1.627 & 0.031 & 0.031 & 0.972 & 0.031 & 0.031 & 0.076 \\
\hline 10 & 0.033 & 0.033 & 0.733 & 0.033 & 0.033 & 0.413 & 0.031 & 0.031 & 0.188 & 0.032 & 0.031 & 1.897 & 0.031 & 0.031 & 0.770 & 0.031 & 0.031 & 0.109 \\
\hline 15 & 0.035 & 0.035 & 0.251 & 0.035 & 0.035 & 0.005 & 0.032 & 0.032 & 0.167 & 0.033 & 0.032 & 2.302 & 0.032 & 0.032 & 0.410 & 0.033 & 0.033 & 0.139 \\
\hline
\end{tabular}




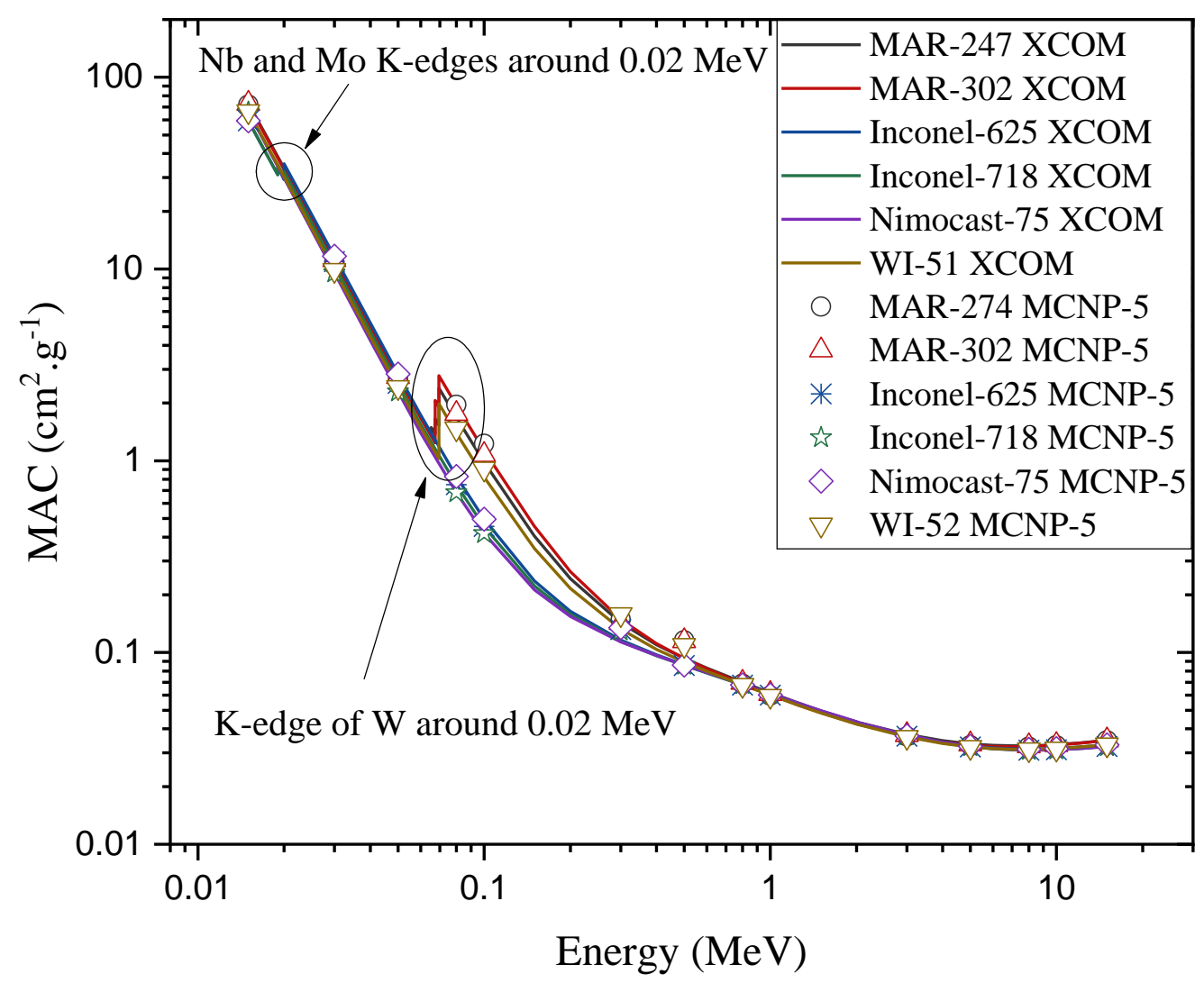

Figure 2. The mass attenuation coefficient (MAC) of the studied alloys using the MCNP-5 code and XCOM software.

The MCNP- 5 simulated MAC values were compared with the values obtained by the XCOM software (Table 2 and Figure 2). The comparison revealed that the simulated and calculated results were close to one another for all the investigated alloys. The comparison also showed that the highest MAC was obtained for alloys encoded as MAR-302 (range $0.035-72.94 \mathrm{~cm}^{2} \cdot \mathrm{g}^{-1}$ ) and MAR-274 (range $0.035-71.98 \mathrm{~cm}^{2} \cdot \mathrm{g}^{-1}$ ). The small variation between the MAC of the MAR-302 and MAR-247 alloys was due to the difference in the main constituent elements of alloys: cobalt and nickel. The lowest MAC was obtained for the alloy encoded as Inconel-625 and varied in the range of $0.0323-59.308 \mathrm{~cm}^{2} \cdot \mathrm{g}^{-1}$ for photon energies between 0.015 and $15 \mathrm{MeV}$.

The half-value layer (HVL) of the studied alloys was theoretically calculated using the simulated MAC for $\gamma$-ray energies between 0.015 and $15 \mathrm{MeV}$ and the results are illustrated in Figure 3. It can be observed that the HVL values were close to one another at low energies such as at $0.015 \mathrm{MeV}$. After that, the HVL values progressively increased with the increase in photon energy due to the PE interaction. Above $0.2 \mathrm{MeV}$, the HVL values steadily increased with an increase in gamma energy, based on the CS process. At energies greater than several MeV, the HVL values were observed to decrease with an increase in photon energy due to the pair production process, which is the main interaction for high energy gamma-rays. The MAR-247 alloy possessed the thinnest HVL, which varied in the range of $0.001-2.159 \mathrm{~cm}$, while the Inconel-625 alloy had the thickest HVL, which varied between 0.001 and $2.604 \mathrm{~cm}$. 


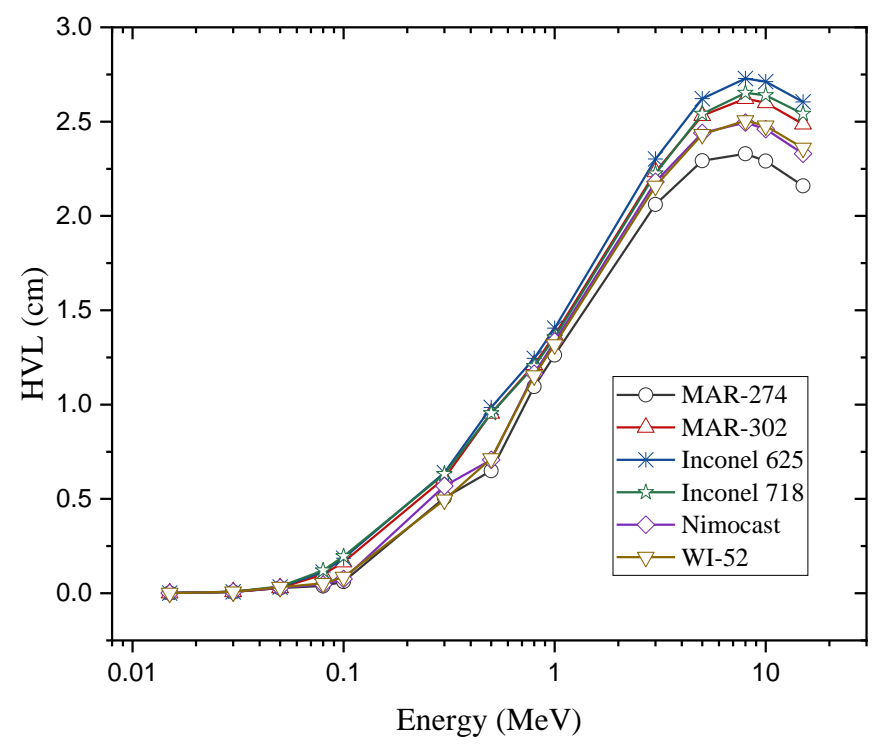

Figure 3. Variation of the half-value layer (HVL) of the studied alloys against the incident gamma-ray energy.

The mean free path (MFP) of the investigated alloys was calculated based on the simulated MAC values for a gamma-ray energy range of $0.015-15 \mathrm{MeV}$. The variation of the MFP versus the gamma photon energies for all selected alloys is shown in Figure 4. The variation of the MFP versus the gamma photon energies is similar to the variation of HVL discussed previously. The lowest MFP was obtained for the MAR-247 alloy and varied between 0.001 and $3.361 \mathrm{~cm}$, while the highest MFP was achieved for the alloy encoded as Inconel- 625 and varied between 0.002 and $3.936 \mathrm{~cm}$. Moreover, the MFP of the studied alloys were compared with other common radiation shielding materials in Figure 4: ordinary concrete, commercial glass RS-253 G18, and lead at some fixed energies $(0.5,1,5$, and $15 \mathrm{MeV})$. The MFP of the studied alloys was lower than the MFP of ordinary concrete and commercial glass RS-253 G18. In contrast, the MFP of the studied alloys was higher than the MFP of Pb, with the MFP for lead varying between 0.0546 and $1.557 \mathrm{~cm}$ for gamma photon energies between 0.5 and $15 \mathrm{MeV}$, respectively.

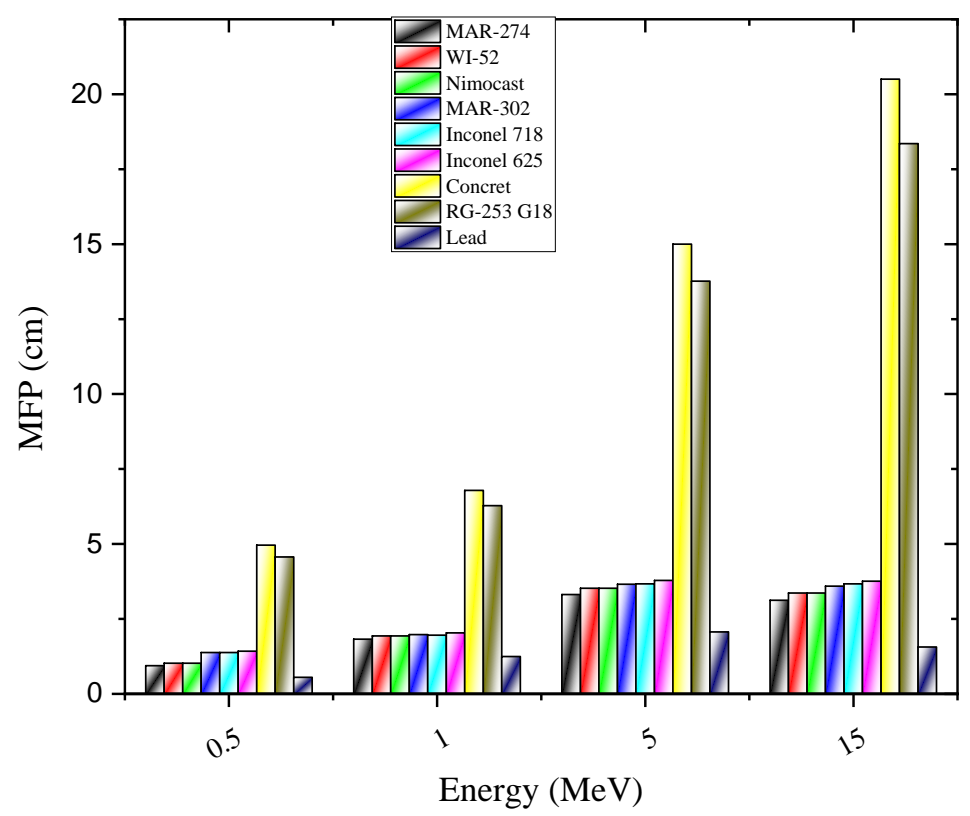

Figure 4. The mean free path (MFP) of the studied alloys versus incident gamma-ray energy. 
The effective atomic number $\left(Z_{\text {eff }}\right)$ is used to describe a multi-element material in terms of its elements. The calculation of $Z_{\text {eff }}$ is based on the calculated MAC, electronic cross section, and atomic cross section. The variation of the $Z_{\text {eff }}$ versus the $\gamma$-ray energies is presented in Figure $5 \mathrm{a}$ for the investigated alloys. The $Z_{\text {eff }}$ trend can be explained through photon interaction phenomena. Values reach their maximum in the PE interaction region because of the dependence of the photoelectric cross-section with $Z^{4-5}$ [34]. In the PE interaction region, two sudden increases appeared at around 0.02 and $0.07 \mathrm{MeV}$. The first increase appeared at around $0.02 \mathrm{MeV}$ for the Inconel-625 and Inconel-718 alloys. This increase was due to the K-absorption edges (X-ray) of $\mathrm{Nb}$ and Mo, which appeared at 0.019 and $0.02 \mathrm{MeV}$, respectively. The second increase was detected at around $0.07 \mathrm{MeV}$ for MAR-247, MAR-302, and WI-52 alloys. This second increase was due to the W K-edges, which appeared at $0.069 \mathrm{MeV}$. Then, the $Z_{\text {eff }}$ values sharply decreased with the increase in $\gamma$-ray energy because of the PE cross-section, which was proportional to $\mathrm{E}^{-3.5}$. In the region where $\mathrm{CS}$ was dominant, $\mathrm{Z}_{\text {eff }}$ demonstrated a moderate reduction with an increase of $\gamma$-ray energy, since the CS cross-section varied with $Z$. Above several $\mathrm{MeV}$, the $Z_{\text {eff }}$ reversed its downward trend and began to increase with an increase in photon energy due to the PP cross-section, which varied with $Z^{2}$.
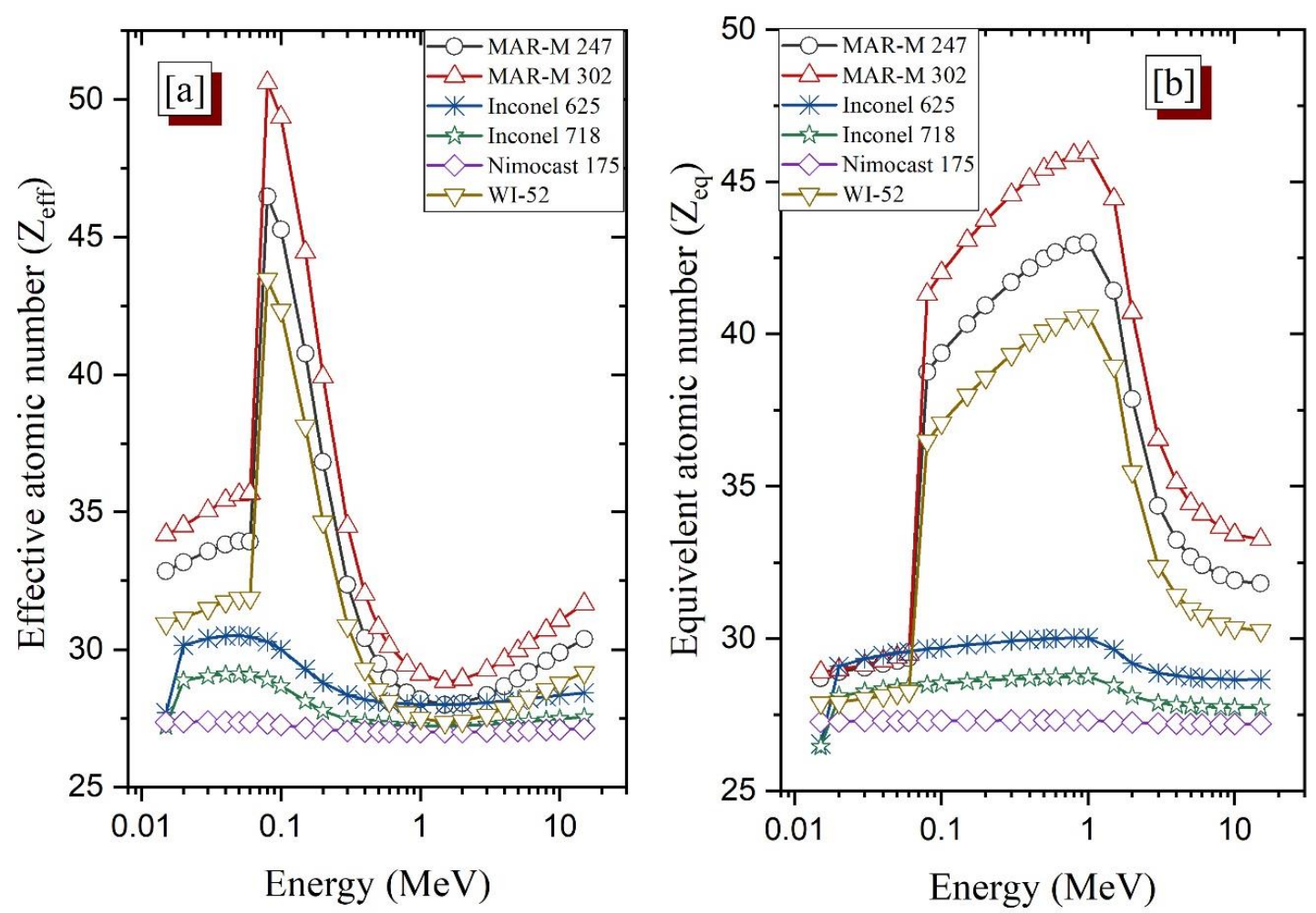

Figure 5. Variation of the atomic number of the investigated alloys versus incident gamma-ray energy: (a) effective atomic number $\left(Z_{\text {eff }}\right)$, (b) the equivalent atomic number $\left(Z_{\text {eq }}\right)$.

The chemical composition of a material plays an important role in its $Z_{\text {eff }}$ value and the value of other shielding parameters. The MAR-302 alloy, with tungsten (W), tantalum (Ta), and hafnium (Hf) contents, possessed the highest $Z_{\text {eff }}$, while Nimocast- 75 had the lowest, which mainly consisted of nickel (Ni) and chromium (Cr).

The equivalent atomic number $Z_{\text {eq }}$ is the first step to calculate the buildup factors of the studied materials and describes the material in term of its equivalent elements. Unlike the $Z_{\text {eff }}$, the $Z_{\text {eq }}$ of the selected alloys is calculated based on the ratio between the Compton scattering mass attenuation coefficient and the total mass attenuation coefficient of the sample at energies of $0.015-15 \mathrm{MeV}$. Figure $5 \mathrm{~b}$ demonstrates that the $Z_{\mathrm{eq}}$ tends to decrease in the energy region where the PE is prevalent. As energy keeps increasing, the $Z_{\mathrm{eq}}$ values have an increasing trend with the increase of the CS interaction 
for all the alloys. At $1 \mathrm{MeV}$, the $\mathrm{Z}_{\mathrm{eq}}$ reached its maximum, varying between 27.31 and 45.96 for the Nimocast-75 and MAR-302 alloys, respectively. Above $1.5 \mathrm{MeV}$, the $Z_{\mathrm{eq}}$ gradually reduced due to the dominancy of the PP interaction inside the studied alloys.

Based on these factors, it can be concluded that the MAR-247 and MAR-302 alloys possess the most desirable shielding characteristics among the investigated alloys, while the Inconel-625 and Inconel-718 alloys possess the least effective shielding ability. The desirable attenuation ability of the MAR-247 and MAR-302 alloys is related to their chemical composition, which contains heavy elements with good shielding characteristics such as tungsten (W), tantalum (Ta), and hafnium (Hf). The less effective shielding characteristics of Inconel-625 and Inconel-718 are also due to their chemical composition, which mainly consists of nickel $(\mathrm{Ni})$ and chromium $(\mathrm{Cr})$.

The energy absorption and exposure buildup factors (EABF and EBF) were calculated according to [30]. The variation of the buildup factors EABF and EBF versus the gamma-ray energy at some penetration depths (PD) between 0.5 and $40 \mathrm{mfp}$ is shown in Figures $6 \mathrm{a}-\mathrm{f}$ and $7 \mathrm{a}-\mathrm{f}$. The lowest EABF and EBF values for the selected alloys were obtained at the lowest tested photon energy. The energy of gamma photons is completely absorbed during the PE interaction. Thus, photons cannot contaminate inside the selected alloys, which reduces the buildup factors. At middle energies where the CS interaction is prevalent, the calculated values of EABF and EBF for all the selected alloys increase as energy increases. As a result of the CS interaction, a secondary photon can be produced and accumulated inside the selected alloys. Thus, the buildup factors greatly increase in the CS interaction region. Past this region, the values of the buildup factors begin to slowly decrease with the increase of photon energy, above $1.5 \mathrm{MeV}$ more specifically. This decrease is due to the photons that have enough energy to create electron-positron pairs with low kinetic energy. For energies greater than $8 \mathrm{MeV}$, the values of EABF and EBF quickly increased with increasing energy, especially at high penetration depths (PD $>20)$. Figures 6 and 7 show that the highest values of EABF and EBF were obtained for the MAR-302 alloy, while the lowest values were obtained for the WI-51 alloy.
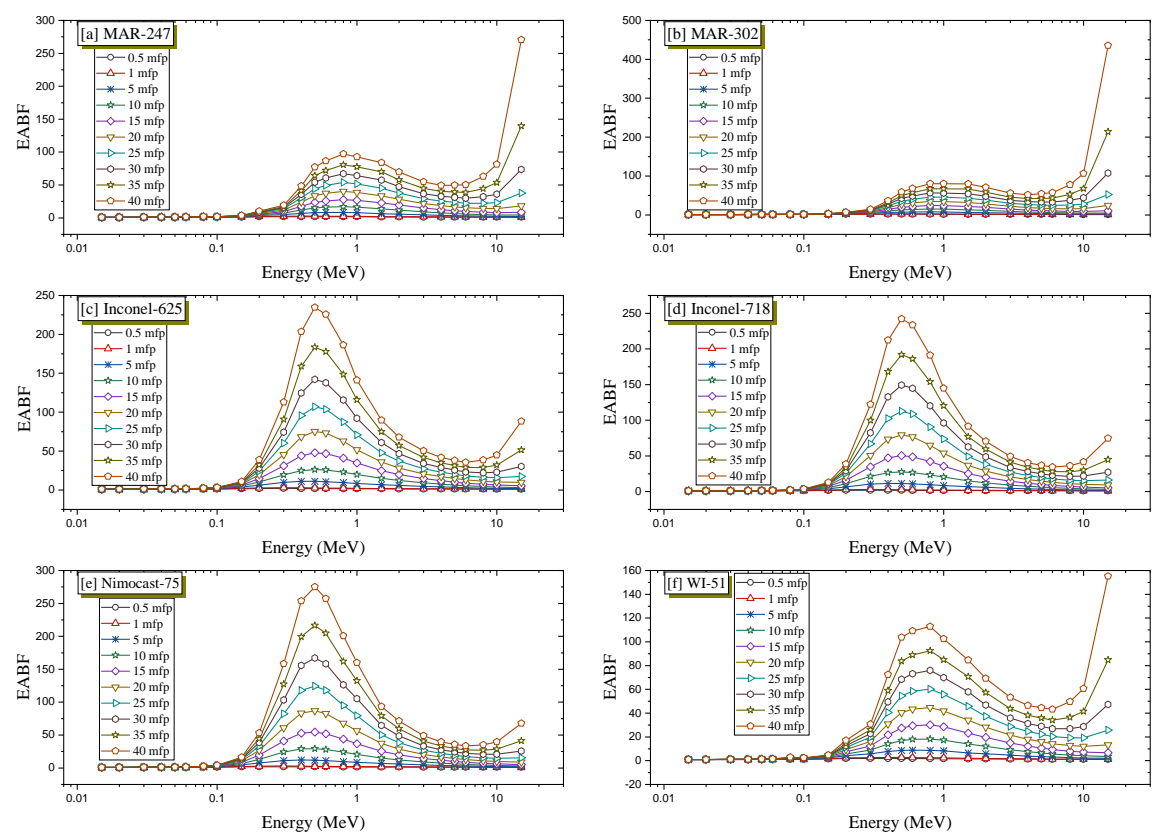

Figure 6. Variation of the energy absorption buildup factor versus the gamma-ray energy at various penetration depths.for the investigated alloys: (a) MAR-247, (b) MAR-302, (c) Inconel-625, (d) Inconel-718, (e) Nimocast-75, (f) WI-51. 

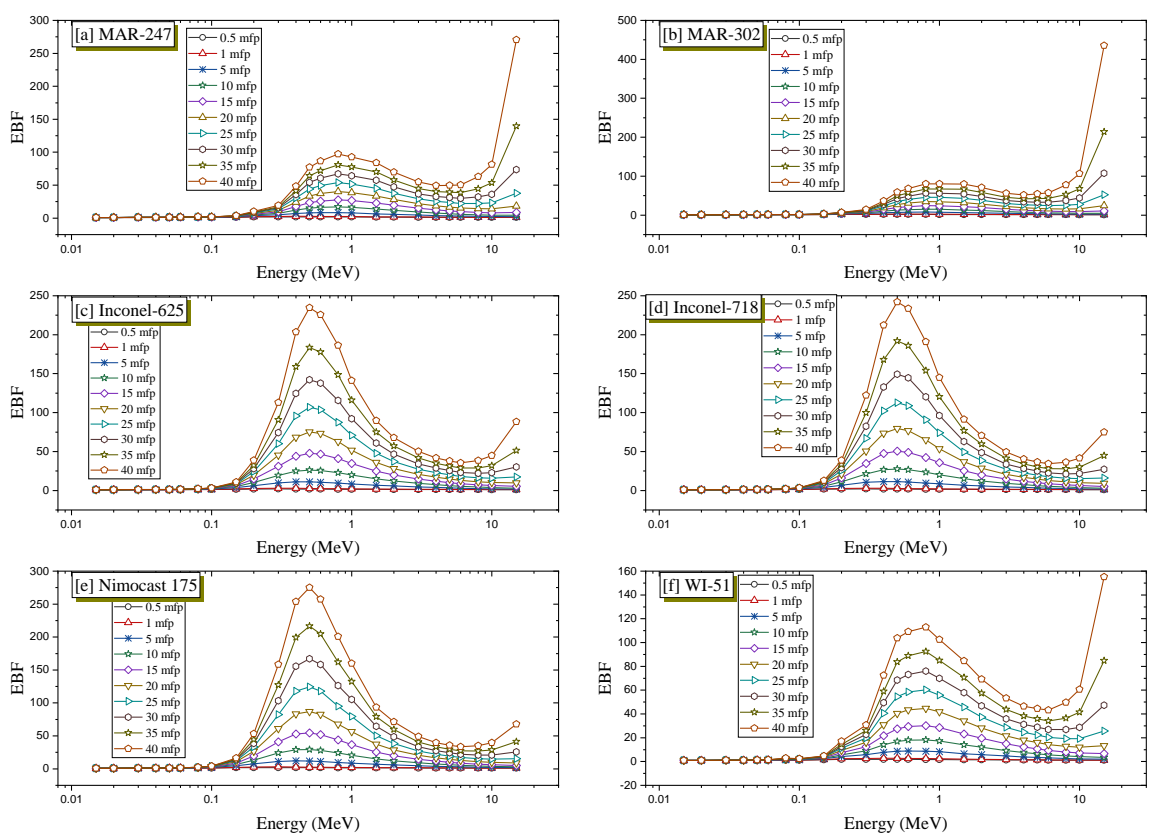

Figure 7. Variation of the exposure buildup factor (EBF) versus the incident gamma-ray energy at various penetration depths for the investigated alloys: (a) MAR-247, (b) MAR-302, (c) Inconel-625, (d) Inconel-718, (e) Nimocast-75, (f) WI-51.

The variation of buildup factors with the penetration depth (PD) for the selected alloys is presented in Figure 8 at some fixed gamma-ray energies $(0.015,1$, and $15 \mathrm{MeV})$. At around $0.015 \mathrm{MeV}$, for all the selected alloys, the values slowly increased with the increase in the PD. At $1 \mathrm{MeV}$, where CS is prevalent, EBF and EABF steadily increased with the increase in PD, especially at high PD ( $\geq 20 \mathrm{mfp})$. Additionally, at high energies, the values quickly increased with the penetration depth, especially for $\mathrm{PD} \geq 20$.
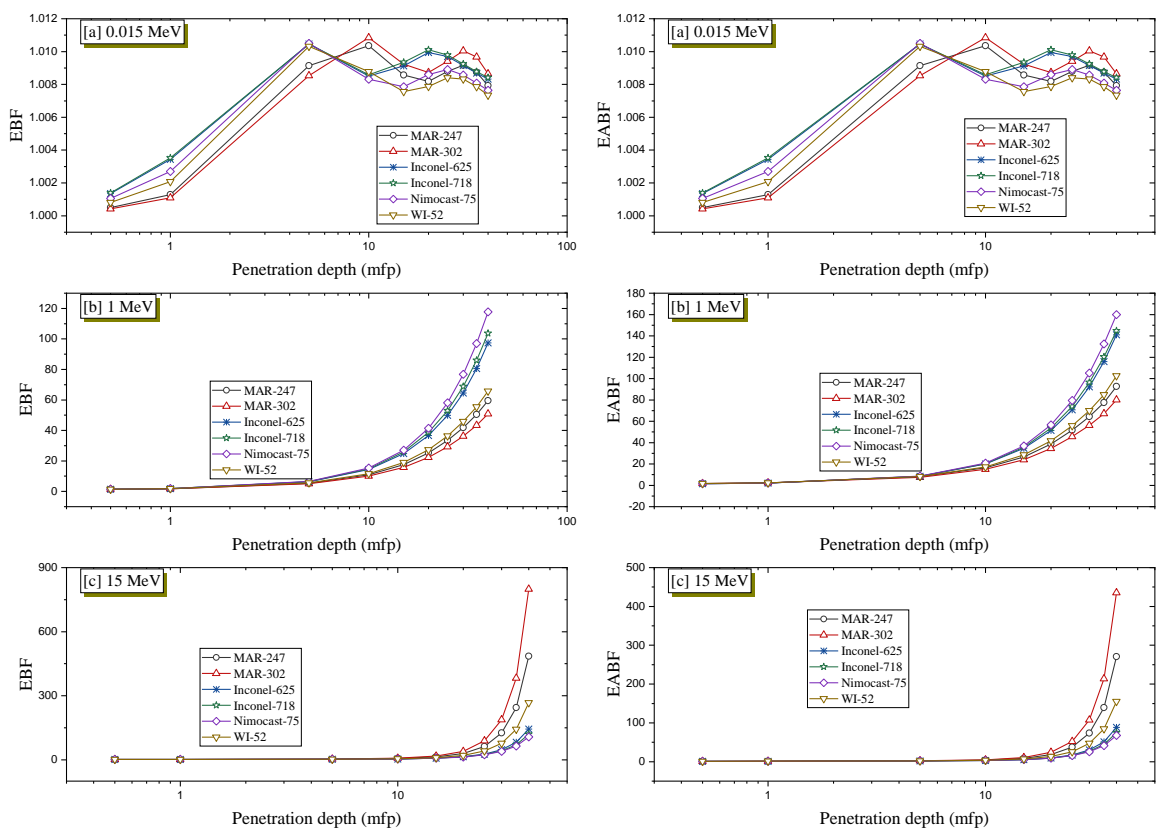

Figure 8. Variation of the buildup factors versus the penetration depth of the studied alloys at some fixed energies: (a) $0.015 \mathrm{MeV}$, (b) $1 \mathrm{MeV}$, (c) $15 \mathrm{MeV}$. 
Furthermore, the ability of the selected alloys to attenuate fast neutrons was evaluated. The effective removal cross-section $\sum_{\mathrm{R}}\left(\mathrm{cm}^{2} \cdot \mathrm{g}^{-1}\right)$ for fast neutrons was calculated according to Equations (5) and (6) [35]

$$
\begin{aligned}
& \sum_{\mathrm{R}}\left(\mathrm{cm}^{2} \cdot \mathrm{g}^{-1}\right)=0.190 \mathrm{Z}^{-0.743},(\mathrm{Z} \leq 8) \\
& \sum_{\mathrm{R}}\left(\mathrm{cm}^{2} \cdot \mathrm{g}^{-1}\right)=0.125 \mathrm{Z}^{-0.565},(\mathrm{Z}>8)
\end{aligned}
$$

Figure 9 illustrates the $\sum_{R}$ of fast neutrons for the selected alloys. The data presented in Figure 9 demonstrates that the $\sum_{R}$ varied between 0.01945 and $0.01841 \mathrm{~cm}^{2} \cdot \mathrm{g}^{-1}$. The highest effective removal cross-section was achieved for the Inconel-718 $\left(\sum_{\mathrm{R}}=0.01945 \mathrm{~cm}^{2} \cdot \mathrm{g}^{-1}\right)$ and Nimocost-75 $\left(\sum_{R}=0.01940 \mathrm{~cm}^{2} \cdot \mathrm{g}^{-1}\right)$ alloys. The alloys also possessed the lowest $Z_{\text {eff }}$ among the selected samples. The lowest effective removal cross-section was achieved by the MAR-302 alloy $\left(\sum_{R}=0.01841 \mathrm{~cm}^{2} \cdot \mathrm{g}^{-1}\right)$ because it possessed the highest $Z_{\text {eff }}$ among the studied alloys.

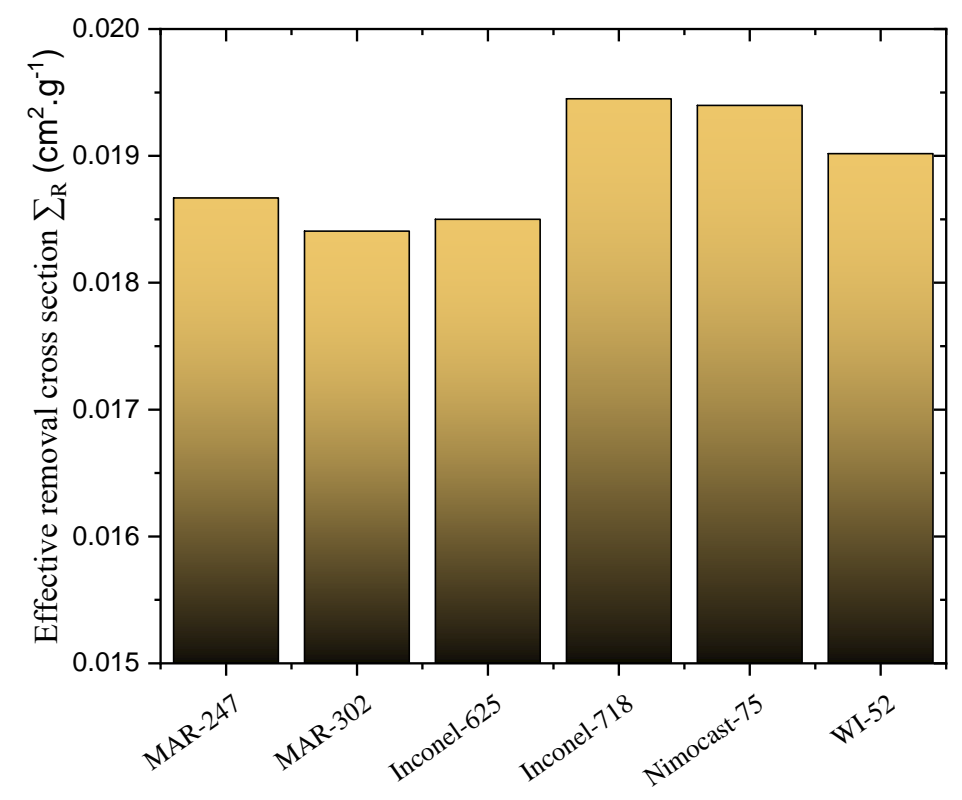

Figure 9. The fast neutron effective removal cross-section of the studied alloys.

Finally, the SRIM program was applied to evaluate the ability of the studied alloys to shield charged particles. Figure 10 shows the variation of the mass stopping power (MSP) and the projected range (PR) versus the kinetic energy of the incident charged particles. The MSP of the charged particles mainly depends on two factors. The first is the kinetic energy of the charged particle. At low energies, the calculated MSP values gradually increase with the increase in the kinetic energy of the incident particles. Around 0.1 and $0.8 \mathrm{MeV}$, the MSP reaches its maximum values for proton and alpha particles, respectively. It should be noted that the MSP for protons reaches its peak at a lower kinetic energy than alpha particles because the mass of a single proton is lower than one alpha particle. The maximum MSP varied between 0.218 and $0.242 \mathrm{MeV} \cdot \mathrm{cm}^{2} \cdot \mathrm{mg}^{-1}$ for protons, while the maximum MSP for alpha particles varied between 0.676 and $0.743 \mathrm{MeV} \cdot \mathrm{cm}^{2} \cdot \mathrm{mg}^{-1}$. As the kinetic energy keeps increasing, the MSP values for both proton and alpha particles drastically decrease, which continues at higher energies. The second factor is the chemical composition of the selected alloys. The alloys with high contents of heavy elements such as W, Hf, and Ta (MAR-247, MAR-302, and WI-52) possessed lower MSP values, while the alloys with light elements (Inconel-625, Inconel-718, and Nimocast-75) possessed much lower MSP values at all kinetic energies for both protons and alpha particles. 

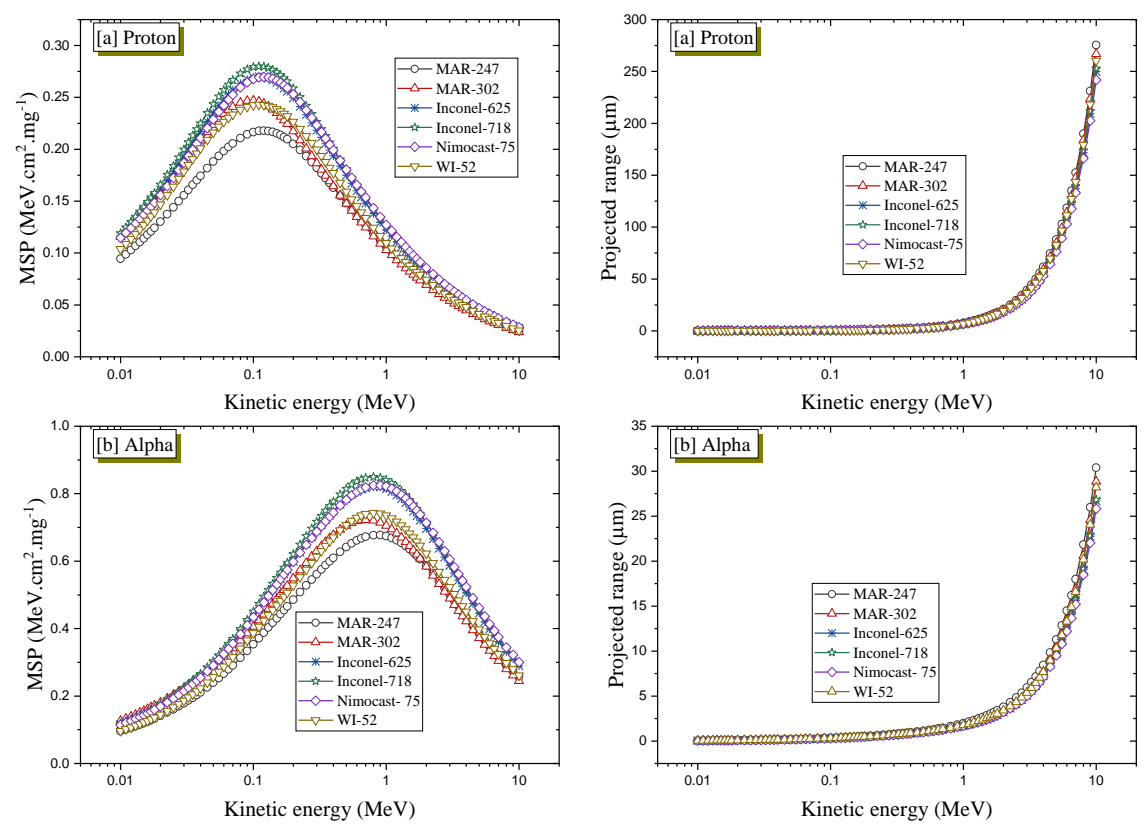

Figure 10. Variation of the mass stopping power (MSP) and the projected range versus the kinetic energy.for the projected particles: (a) Protons, (b) Alpha particles versus.

Figure 10 illustrates the variation of the projected range (PR) for protons and alpha particles against the kinetic energy of the incident particles. The calculated PR increased exponentially with the increase of the kinetic energy of the charged particles. The highest PR was obtained at a kinetic energy of $10 \mathrm{MeV}$ for the MAR-247 alloy (a PR equal to $275.42 \mu \mathrm{m}$ for both proton and alpha particles, respectively), while the lowest PR was obtained for the Nimocast-75 alloy (with a PR equal to 241.49 and $25.83 \mu \mathrm{m}$ for both particles, respectively).

\section{Conclusions}

In this study, the radiation shielding ability of six alloys coded as MAR-302, MAR-247, Inconel-625, Inconel-718, Nimocast-75, and WI-52 were evaluated. The studied alloys had a different chemical composition and their densities varied in the range of $8.22-9.21 \mathrm{~g} \mathrm{~cm}^{-3}$. The gamma radiation shielding features were simulated using the MCNP- 5 code in the energy range between 0.015 and $15 \mathrm{MeV}$. The XCOM program was used to validate the simulated MAC values for the selected alloys. Additionally, the SRIM program was used to calculate the stopping power and projected range of protons and alpha particles. The current study recorded the following outcomes:

1. The highest MAC was achieved for thee eMAR-302 and MAR-247 alloys and varied between $0.035-72.938 \mathrm{~cm}^{2} \cdot \mathrm{g}^{-1}$ and $0.035-71.98 \mathrm{~cm}^{2} \cdot \mathrm{g}^{-1}$, respectively, while the lowest MAC was achieved for Inconel-718 and Nimocast-75 and varied in the range of $0.033-59.25 \mathrm{~cm}^{2} \cdot \mathrm{g}^{-1}$ and $0.032-59.30 \mathrm{~cm}^{2} \cdot \mathrm{g}^{-1}$, respectively.

2. The obtained results between the simulated MAC using the eMCNP-5 code and theoretical MAC using the XCOM database were proven to greatly agree with each other.

3. The thickest HVL was achieved for the alloy encoded as Inconel-625 and varied between 0.001 and $2.604 \mathrm{~cm}$, while MAR-247 had the thinnest HVL, which varied between 0.001 and $2.159 \mathrm{~cm}$.

4. The highest values for the $Z_{\text {eff }}$ and $Z_{\text {eq }}$ were achieved for the alloys encoded as MAR-302 and MAR-247.

5. The lowest fast neutron effective removal cross-section was obtained for MAR-302 $\left(\sum_{\mathrm{R}}=0.01841 \mathrm{~cm}^{2} \cdot \mathrm{g}^{-1}\right)$, while Inconel-718 $\left(\sum_{\mathrm{R}}=0.01945 \mathrm{~cm}^{2} \cdot \mathrm{g}^{-1}\right)$ and Nimocost-75 $\left(\sum_{\mathrm{R}}=0.01940 \mathrm{~cm}^{2} \cdot \mathrm{g}^{-1}\right)$ had the greatest values. 
According to the aforementioned results, the studied alloys (especially MAR-302 and MAR-247) were proven to be highly effective against charged-particles and fast neutrons. Thus, MAR-302 and MAR-247 are desirable shielding materials for gamma-ray applications, despite their low fast neutron effective removal cross-section.

Author Contributions: Conceptualization, M.I.S.; Methodology, M.I.S.; Software, E.L.; Validation, E.I. and K.M.K.; Formal analysis, F.Q.M.; Investigation, M.I.S.; Resources, M.I.S.; Data curation, K.A.M. and M.I.S.; Writing-original draft preparation, M.I.S.; Writing-review and editing, M.U.K.; Visualization, E.L.; Supervision, K.M.K.; Project administration, M.R.I.F.; Funding acquisition, M.R.I.F. All authors have read and agreed to the published version of the manuscript.

Funding: This work was funded by the Research Universiti Grant, Universiti Kebangsaan Malaysia, Geran Universiti Penyelidikan (GUP), code: 2018-134.

Conflicts of Interest: The authors declare no conflict of interest.

\section{References}

1. Mahmoud, K.A.; Tashlykov, O.L.; Wakil, A.F.E.; Zakaly, H.M.H.; Aassy, I.E.E. Investigation of radiation shielding properties for some building materials reinforced by basalt powder. In Proceedings of the AIP Conference Proceedings, Yekaterinburg, Russia, 23-25 December 2019.

2. Mahmoud, K.A.; Sayyed, M.I.; Tashlykov, O.L. Gamma ray shielding characteristics and exposure buildup factor for some natural rocks using MCNP-5 code. Nucl. Eng. Technol. 2019, 51, 1835-1841. [CrossRef]

3. Vaiserman, A.; Koliada, A.; Zabuga, O.; Socol, Y. Health Impacts of Low-Dose Ionizing Radiation: Current Scientific Debates and Regulatory Issues. Dose-Response 2018, 16, 1-27. [CrossRef] [PubMed]

4. Choi, T.A.; Costes, S.V.; Abergel, R.J. Understanding the health impacts and risks of exposure to radiation. In Reflections on the Fukushima Daiichi Nuclear Accident: Toward Social-Scientific Literacy and Engineering Resilience; Springer International Publishing: Cham, Switzerland, 2015; ISBN 9783319120904.

5. Mahmoud, K.A.; Tashlykov, O.L.; El Wakil, A.F.; El Aassy, I.E. Aggregates grain size and press rate dependence of the shielding parameters for some concretes. Prog. Nucl. Energy 2020, 118, 103092. [CrossRef]

6. Ouda, A.S. Development of high-performance heavy density concrete using different aggregates for gamma-ray shielding. Prog. Nucl. Energy 2015, 79, 48-55. [CrossRef]

7. Kaur, U.; Sharma, J.K.; Singh, P.S.; Singh, T. Comparative studies of different concretes on the basis of some photon interaction parameters. Appl. Radiat. Isot. 2012, 70, 233-240. [CrossRef]

8. Waly, E.S.A.; Bourham, M.A. Comparative study of different concrete composition as gamma-ray shielding materials. Ann. Nucl. Energy 2015, 85, 306-310. [CrossRef]

9. Yilmaz, E.; Baltas, H.; Kiris, E.; Ustabas, I.; Cevik, U.; El-Khayatt, A.M. Gamma ray and neutron shielding properties of some concrete materials. Ann. Nucl. Energy 2011, 38, 2204-2212. [CrossRef]

10. Gencel, O.; Bozkurt, A.; Kam, E.; Korkut, T. Determination and calculation of gamma and neutron shielding characteristics of concretes containing different hematite proportions. Ann. Nucl. Energy 2011, 38, 2719-2723. [CrossRef]

11. Al-Hadeethi, Y.; Sayyed, M.I. Analysis of borosilicate glasses doped with heavy metal oxides for gamma radiation shielding application using Geant4 simulation code. Ceram. Int. 2019, 45, 24858-24864. [CrossRef]

12. Al-Hadeethi, Y.; Sayyed, M.I. A comprehensive study on the effect of $\mathrm{TeO} 2$ on the radiation shielding properties of $\mathrm{TeO} 2-\mathrm{B} 2 \mathrm{O} 3-\mathrm{Bi} 2 \mathrm{O} 3-\mathrm{LiF}-\mathrm{SrCl} 2$ glass system using Phy-X/PSD software. Ceram. Int. 2020, 46, 6136-6140. [CrossRef]

13. Al-Hadeethi, Y.; Sayyed, M.I.; Mohammed, H.; Rimondini, L. X-ray photons attenuation characteristics for two tellurite based glass systems at dental diagnostic energies. Ceram. Int. 2020, 46, 251-257. [CrossRef]

14. Abouhaswa, A.S.; Sayyed, M.I.; Mahmoud, K.A.; Al-Hadeethi, Y. Direct influence of mercury oxide on structural, optical and radiation shielding properties of a new borate glass system. Ceram. Int. 2020, 46, 17978-17986. [CrossRef]

15. Divina, R.; Marimuthu, K.; Mahmoud, K.A.; Sayyed, M.I. Physical and structural effect of modifiers on dysprosium ions incorporated boro-tellurite glasses for radiation shielding purposes. Ceram. Int. 2020, 46, 17929-17937. [CrossRef]

16. Kopittke, P.M.; Asher, C.J.; Kopittke, R.A.; Menzies, N.W. Toxic effects of Pb2+ on growth of cowpea (Vigna unguiculata). Environ. Pollut. 2007, 150, 280-287. [CrossRef] 
17. Akman, F.; Sayyed, M.I.; Kaçal, M.R.; Tekin, H.O. Investigation of photon shielding performances of some selected alloys by experimental data, theoretical and MCNPX code in the energy range of $81 \mathrm{keV}-1333 \mathrm{keV}$. J. Alloys Compd. 2019, 772, 516-524. [CrossRef]

18. Agar, O.; Sayyed, M.I.; Akman, F.; Tekin, H.O.; Kaçal, M.R. An extensive investigation on gamma ray shielding features of Pd/Ag-based alloys. Nucl. Eng. Technol. 2019, 51, 853-859. [CrossRef]

19. Akman, F.; Kaçal, M.R.; Sayyed, M.I.; Karataş, H.A. Study of gamma radiation attenuation properties of some selected ternary alloys. J. Alloys Compd. 2019, 782, 315-322. [CrossRef]

20. Kaur, S.; Kaur, A.; Singh, P.S.; Singh, T. Scope of Pb-Sn binary alloys as gamma rays shielding material. Prog. Nucl. Energy 2016, 93, 277-286. [CrossRef]

21. Singh, J.; Singh, H.; Sharma, J.; Singh, T.; Singh, P.S. Fusible alloys: A potential candidate for gamma rays shield design. Prog. Nucl. Energy 2018, 106, 387-395. [CrossRef]

22. Singh, T.; Kaur, A.; Sharma, J.; Singh, P.S. Gamma rays' shielding parameters for some Pb-Cu binary alloys. Eng. Sci. Technol. an Int. J. 2018, 21, 1078-1085. [CrossRef]

23. Aygün, B.; Şakar, E.; Korkut, T.; Sayyed, M.I.; Karabulut, A.; Zaid, M.H.M. Fabrication of Ni, Cr, W reinforced new high alloyed stainless steels for radiation shielding applications. Results Phys. 2019, 12, 1-6. [CrossRef]

24. Chen, X.; Liu, L.; Liu, J.; Pan, F. Microstructure, electromagnetic shielding effectiveness and mechanical properties of Mg-Zn-Y-Zr alloys. Mater. Des. 2015, 65, 360-369. [CrossRef]

25. Singh, V.P.; Badiger, N.M. An investigation on gamma and neutron shielding efficiency of lead-free compounds and alloys. Indian J. Pure Appl. Phys. 2016, 54, 443-448.

26. Mankins, W.L.; Lamb, S. Nickel and Nickel Alloys, in ASM Metals Handbook, VOL.2, Properties and Selection: Nonferrous Alloys and Special-Purpose Materials; ASM International: Novelty, OH, USA, 1990; ISBN 978-1-62708-162-7. [CrossRef]

27. X-5 Monte Carlo Team. MCNP-A General Monte Carlo N-Particle Transport Code, Version 5, LA-CP-03-0245; University of California, Los Alamos National Laboratory: Los Alamos, NM, USA, 2003.

28. Mansour, A.; Sayyed, M.I.; Mahmoud, K.A.; Şakar, E.; Kovaleva, E.G. Modified halloysite minerals for radiation shielding purposes. J. Radiat. Res. Appl. Sci. 2020, 13, 94-101. [CrossRef]

29. Mahmoud, K.A.; Tashlykov, O.L.; Sayyed, M.I.; Kavaz, E. The role of cadmium oxides in the enhancement of radiation shielding capacities for alkali borate glasses. Ceram. Int. 2020. [CrossRef]

30. Şakar, E.; Özpolat, Ö.F.; Alım, B.; Sayyed, M.I.; Kurudirek, M. Phy-X/PSD: Development of a user friendly online software for calculation of parameters relevant to radiation shielding and dosimetry. Radiat. Phys. Chem. 2020, 166, 108496. [CrossRef]

31. Ziegler, J.F.; Ziegler, M.D.; Biersack, J.P. SRIM-The stopping and range of ions in matter (2010). Nucl. Instrum. Methods Phys. Res. B 2010, 268, 1818. [CrossRef]

32. Rammah, Y.S.; Mahmoud, K.A.; Kavaz, E.; Kumar, A.; El-Agawany, F.I. The role of PbO/Bi2O3 insertion on the shielding characteristics of novel borate glasses. Ceram. Int. 2020, 46, 23357-23368. [CrossRef]

33. El-Agawany, F.I.; Tashlykov, O.L.; Mahmoud, K.A.; Rammah, Y.S. The radiation-shielding properties of ternary SiO2-SnO-SnF2 glasses: Simulation and theoretical study. Ceram. Int. 2020, 46, 23369-23378. [CrossRef]

34. El-Agawany, F.I.; Mahmoud, K.A.; Kavaz, E.; El-Mallawany, R.; Rammah, Y.S. Evaluation of nuclear radiation shielding competence for ternary Ge-Sb-S chalcogenide glasses. Appl. Phys. A Mater. Sci. Process. 2020, 126, 1-11. [CrossRef]

35. El Abd, A.; Mesbah, G.; Mohammed, N.M.A.; Ellithi, A. A simple Method for Determining the Effective Removal Cross Section for Fast Neutrons. J. Radiat. Nucl. Appl. 2017, 2, 53-58. [CrossRef]

Publisher's Note: MDPI stays neutral with regard to jurisdictional claims in published maps and institutional affiliations.

(C) 2020 by the authors. Licensee MDPI, Basel, Switzerland. This article is an open access article distributed under the terms and conditions of the Creative Commons Attribution (CC BY) license (http://creativecommons.org/licenses/by/4.0/). 